\title{
Identification of Heat Tolerance in Chinese Wildgrape Germplasm Resources
}

\author{
Yongxiang Liu ${ }^{1, \dagger}$, Jianfu Jiang ${ }^{1,+}{ }^{+}$, Xiucai Fan ${ }^{1}$, Ying Zhang ${ }^{1}$, Jiuyun $W^{2}{ }^{2}$, Lijun Wang ${ }^{3, *}$ \\ and Chonghuai Liu ${ }^{1, *}$ \\ 1 Zhengzhou Fruit Research Institute, Chinese Academy of Agricultural Sciences, Zhengzhou 450009, China; \\ yongxiangliu.echo@gmail.com (Y.L.); jiangjianfu@caas.cn (J.J.); fanxiucai@caas.cn (X.F.); \\ zhangying07@caas.cn (Y.Z.) \\ 2 Turpan Research Institute of Agricultural Sciences, Xinjiang Academy of Agricultural Sciences, \\ Ürümqi 838000, China; atz8@ncepu.edu.cn \\ 3 Beijing Key Laboratory of Grape Science and Enology and CAS Key Laboratory of Plant Resources, \\ Institute of Botany, Chinese Academy of Sciences, Beijing 100093, China \\ * Correspondence: ljwang@ibcas.ac.cn (L.W.); liuchonghuai@caas.cn (C.L.); Tel.: +86-19903866269 (L.W.); \\ $+86-13661022029$ (C.L.) \\ + These authors contributed equally to the article.
}

Received: 16 September 2020; Accepted: 14 October 2020; Published: 19 October 2020

\begin{abstract}
Global climate warming will significantly impact grapevine growth and development, and thus grape and wine industries worldwide. Heat-tolerant germplasms are very valuable for grapevine breeding programs. In this study, we assessed the thermotolerance of 247 wild grape accessions by chlorophyll fluorescence parameter $\left(F_{v} / F_{m}\right)$ under critical high temperature according to $\mathrm{Xu}$ et al. in 2016, 2017, and 2018. The results showed that 36 grape accessions showed strong heat tolerance. Therefore, these accessions can be used as parents for breeding heat-tolerant grape cultivars.
\end{abstract}

Keywords: Vitis; high temperature; $F_{v} / F_{m}$

\section{Introduction}

Global warming is predicted to cause an increase of $2-6{ }^{\circ} \mathrm{C}$ in ambient temperature by the end of the 21st century [1]. This increase in temperature could be a rate-limiting factor affecting plant growth and development [2]. Grapevine is a globally important fruit crop [3]. Grapevine growth and development are relatively sensitive to high temperature [4], as berry ripening and yield are strongly affected if air temperature exceeds $35^{\circ} \mathrm{C}$ [5]. Meanwhile, in many grape-producing areas, the maximum midday air temperature may exceed $42^{\circ} \mathrm{C}$, and in some regions, it may exceed $45^{\circ} \mathrm{C}$. The significant impact of high temperature on viticulture has been shown previously [6].

High temperatures can cause a series of changes in plant physiological and biochemical processes $[7,8]$. The extent of heat damage in grapevine leaves depends on the magnitude and duration of the stress [9], leaf age [10], and genotype [11]. Different research methods have been used to study grapevine responses to heat stress, such as chlorophyll fluorescence [12], electrolyte leakage [13,14], and photosynthetic $\mathrm{O}_{2}$ evolution rate [15]. Chlorophyll fluorescence investigates the physiological state of photosystem II (PSII), and it has been widely used as a parameter for evaluating plant responses to many environmental stress phenomena on leaves $[10,16,17] . F_{v} / F_{m}$ describes the maximal quantum efficiency of photosystem II, and is the most common method used to measure chlorophyll fluorescence; the ratio is inversely proportional to heat-damage intensity in PSII reaction centers $[18,19]$. In recent years, heat-stress damage was often evaluated through change of $F_{v} / F_{m}$ values in many plants including grape $[10,20-22]$. Previous studies have shown that $F_{v} / F_{m}$ values of two 
grapevine cultivars decreased in response to combined drought and high-temperature stress in the presence of arbuscular mycorrhiza [23]. Similarly, high temperature $\left(50{ }^{\circ} \mathrm{C}\right)$ decreased $F_{v} / F_{m}$ in grape cultivars 'Hong Yuli' and 'Red seedless' [14]. Chlorophyll fluorescence parameter $F_{v} / F_{m}$ is a rapid, sensitive, and convenient method for measuring heat injury in grapevine. Moreover, the results from the evaluation of germplasm with this method are highly reproducible, as shown by the correlation analysis between different years and different months [10,24].

China is one of the geographical centers of origin of wild grapevines [25]. At present, there are many studies on the cold and drought tolerance of wild grapes [26-28]; however, the heat tolerance of wild grapes has been largely unknown. Heat tolerance of Vitis davidii was reported in previous studies $[10,14]$, but there are few reports on the heat tolerance of other wild grape species. The immediacy of global climate warming has recently triggered very active research efforts on heat tolerance of wild plants [29], as there is an urgent need to breed heat-tolerant commercial cultivars. The Zhengzhou Fruit Research Institute collected a large number of wild grapes as the National Grape Germplasm Repository of China. We chose 247 accessions from these resources and evaluated their heat tolerances by $F_{v} / F_{m}$ under critical high temperature $\left(47^{\circ} \mathrm{C}\right)$ according to $\mathrm{Xu}$ et al. [10]. The germplasm identified with strong heat tolerance would be used in grape breeding programs.

\section{Materials and Methods}

\subsection{Plant Materials}

A total of 247 assessed grape accessions belonging to 28 different species were collected from Yunnan, Hubei, Hunan, Guangxi, Henan, and Shandong provinces in China (Supplementary Table S1), which were planted in the spring of 1998 in the Zhengzhou National Grape Germplasm Repository (ZNGGR) in Zhengzhou ( $38^{\circ} 48^{\prime} \mathrm{N}, 113^{\circ} 42^{\prime} \mathrm{E} ; 114 \mathrm{~m}$ a.s.l.) in China. The average annual temperature of Zhengzhou is $14.2^{\circ} \mathrm{C}$, and the highest temperature is $43^{\circ} \mathrm{C}$ from July to September. There are more than $2400 \mathrm{~h}$ of sunshine annually. The annual average rainfall is $660 \mathrm{~mm}$ and is mostly concentrated from June to October. Grapevines were planted $1.2 \mathrm{~m}$ apart within rows and $2.5 \mathrm{~m}$ apart between the rows with a north-south orientation. Grapevines were trained to bilateral cordons all under similar soil, irrigation, pruning, and disease control management.

\subsection{Heat Treatment and Measurement of $F_{v} / F_{m}$}

The study was continuously conducted in July 2016, 2017, and 2018. Each accession was investigated with three biological replicates (three grapevines), while five leaves as technology replicates were sampled in the fifth to seventh healthy expanded leaves from base to top on the shoots in a grapevine. Leaf discs, $3 \mathrm{~cm}$ in diameter, were punched from detached sampled leaves; the discs were wrapped in a wet filter paper and placed in aluminum specimen boxes, and then floated in a water bath at $47^{\circ} \mathrm{C}\left(25^{\circ} \mathrm{C}\right.$ for control, Supplementary Table S2) in the dark. After $40 \mathrm{~min}$, the leaf discs were cooled down at room temperature for $20 \mathrm{~min}$ in the dark [10]. $F_{v} / F_{m}$ value was measured using a pulse-amplitude-modulation fluorometer (IMAGING-PAM, Heinz Walz GmbH, Effeltrich, Germany).

\subsection{Data Analysis}

Statistic was carried out using IBM SPSS Statistics (Statistical Product and Service Solutions) program, ver. 21.0 (August 2012, IBM Corporation, Somers, NY, USA). Data in tables and figures are means and standard errors representing three biological replicates. Significant differences among means were determined by Duncan's multiple range comparison test at a probability level of $p<0.05$.

\section{Results}

The $F_{v} / F_{m}$ values were used to assess the level of heat tolerance of 247 wild grape accessions belonging to 28 species. The higher $F_{v} / F_{m}$ values indicate stronger heat tolerance. In Figure 1 , we used boxplots to show the change in $F_{v} / F_{m}$ values. In general, the evaluation results in consecutive three years 
(2016, 2017, and 2018) are consistent. The heat tolerances in V. heyneana Subsp ficifolia, V. pseudoreticulata, $V$. davidii, V. heyneana, $V$. amurensis, $V$. adenoclada, $V$. wuhanensis are strong, while $V$. piasezkii, $V$. bryoniifolia, $V$. betulifolia, $V$. rotundifolia, and $V$. wilsonae are medium, while those in $V$. yunnanensis, V. riparia, $V$. rupestris, and $V$. romanetii are weak. In some species, the difference in heat tolerance among accessions is very large. The top 10 grape varieties with high heat tolerance are listed in Table 1.

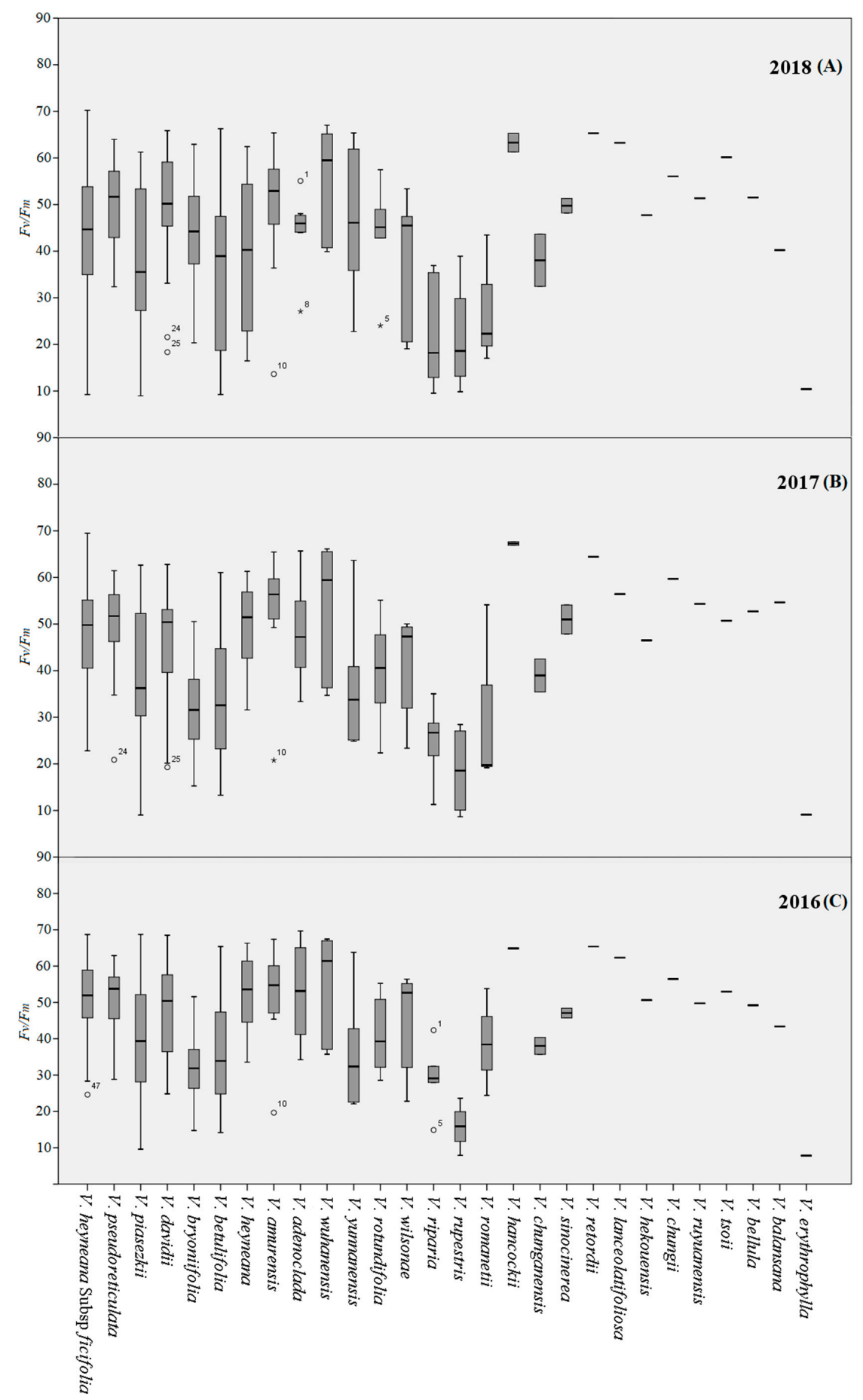

Figure 1. $F_{v} / F_{m}$ in different grapevine species in 2018 (A), 2017 (B), and 2016 (C). The horizontal lines in the interior of each box are the median values. The height in a box is equal to the interquartile distance, indicating the distribution for $50 \%$ of the data. Approximately $99 \%$ of the data falls inside the whiskers (the straight lines extending from the top and bottom of the box). The data outside these whiskers are indicated by blank circles. 
Table 1. The top 10 accessions or species in wild grape resource evaluated by $F_{v} / F_{m}$ in the study.

\begin{tabular}{|c|c|c|c|c|c|c|c|c|}
\hline No. & Species & Accession & Origin & $\begin{array}{c}2016 \\
F_{v} / F_{m}\end{array}$ & $\begin{array}{c}2017 \\
\boldsymbol{F}_{v} / \boldsymbol{F}_{m}\end{array}$ & $\begin{array}{c}2018 \\
F_{v} / F_{m}\end{array}$ & Average Value ${ }^{1}$ & Rank $^{2}$ \\
\hline 1 & V. heyneana & Shibanyan 11 & Henan & $0.6870 \pm 0.0097 a$ & $0.6652 \pm 0.0274 \mathrm{~b}$ & $0.7022 \pm 0.0110 \mathrm{a}$ & $0.6848 \pm 0.0160$ & I \\
\hline 2 & Subsp ficifolia & Shibanyan 5 & Henan & $0.6096 \pm 0.0233 \mathrm{de}$ & $0.6610 \pm 0.0194 \mathrm{~b}$ & $0.6694 \pm 0.0103 b$ & $0.6467 \pm 0.0177$ & I \\
\hline 106 & V. davidii & Meilingshan 1301 & Jiangxi & $0.6850 \pm 0.0066 a$ & $0.6272 \pm 0.0311 a$ & $0.6580 \pm 0.0073 a$ & $0.6567 \pm 0.0150$ & I \\
\hline 181 & V. amurensis & Shuangyou & Unknown & $0.6574 \pm 0.0212 \mathrm{a}$ & $0.6546 \pm 0.0035 a$ & $0.6540 \pm 0.0107 \mathrm{a}$ & $0.6553 \pm 0.0118$ & I \\
\hline 199 & & Dawu 1701 & Hubei & $0.6698 \pm 0.0057 \mathrm{ab}$ & $0.6554 \pm 0.0045 a$ & $0.6704 \pm 0.0021 \mathrm{a}$ & $0.6652 \pm 0.0041$ & I \\
\hline 200 & V. wuhanensis & Jingshan 1708 & Hubei & $0.6744 \pm 0.0038 a$ & $0.6612 \pm 0.0058 \mathrm{a}$ & $0.6406 \pm 0.0043 c$ & $0.6587 \pm 0.0047$ & I \\
\hline 201 & & Xianning 1710 & Hubei & $0.6602 \pm 0.0047 b$ & $0.6508 \pm 0.0051 a$ & $0.6516 \pm 0.0090 \mathrm{~b}$ & $0.6542 \pm 0.0063$ & I \\
\hline 233 & & Ruian 1610 & Zhejiang & $0.6478 \pm 0.0019 a$ & $0.6764 \pm 0.0067 a$ & $0.6528 \pm 0.0028 \mathrm{a}$ & $0.6590 \pm 0.0038$ & I \\
\hline 234 & hancockii & Lingye 945 & Unknown & $0.6498 \pm 0.0111 a$ & $0.6692 \pm 0.0129 a$ & $0.6130 \pm 0.0069 b$ & $0.6440 \pm 0.0103$ & $\mathrm{I}$ \\
\hline 239 & $V$. retordii & Luocheng 1602 & Guangxi & $0.6538 \pm 0.0038$ & $0.6444 \pm 0.0250$ & $0.6532 \pm 0.0044$ & $0.6505 \pm 0.0111$ & I \\
\hline
\end{tabular}

Note: Average value ${ }^{1}$ is the average for three years. $F_{v} / F_{m}$ values are means \pm S.E.; different letters indicate means are significantly different at $p<0.05$. Rank ${ }^{2}$ is the classification of heat resistance of different grapevine varieties by SPSS.

Based on cluster analysis and according to the average values of $F_{v} / F_{m}$ for the three years in the study (Supplementary Table S1), the 247 grape accessions were divided into five major classes-I (high heat-tolerant type), II (heat-tolerant type), III (medium heat-tolerant type), IV (medium heat-sensitive type), and V (heat-sensitive type). The results of this comprehensive evaluation from 2016 to 2018 showed that 36 wild grape accessions were highly heat-tolerant (I class). They are mainly distributed in Henan, Hubei, Jiangxi, and Fujian provinces; nearly 75 grape accessions were heat-tolerant (II), mostly distributed in Henan, Yunnan, Zhejiang, and Fujian provinces. In contrast, 29 grape accessions were sensitive types (V class), mainly distributed in Henan and Jiangxi provinces. Our study found significant intraspecific differences for heat tolerance, such as 'Shibanyan' $11\left(1, F_{v} / F_{m}=0.6848\right)$ and 'Songshan' $\left(49, F_{v} / F_{m}=0.2459\right)$ in $V$. heyneana Subsp ficifolia species, or 'Fujian' $\left(50, F_{v} / F_{m}=0.6211\right)$ and 'Tongmu 1 ' $\left(78, F_{v} / F_{m}=0.3224\right)$, both belonging to $V$. pseudoreticulata.

The $F_{v} / F_{m}$ of the 247 grape accessions ranged from 0.0783 to 0.7022 . In 2016, the highest $F_{v} / F_{m}$ is 0.6966 and is recorded for $V$. Adenoclada (No.191, in Supplementary Table S1) and the lowest (0.0783) is for $V$. erythrophylla 'Fuliang 1605' (247). The median is the representative value of all the unit sign values determined by its position in all the sign values, which is not affected by the maximum or minimum value of the distribution series, thus improving the representativeness of the median to the distribution series to a certain extent. As shown in Figure 1 and Table 1 , the median $F_{v} / F_{m}$ differed significantly among the 28 Vitis species evaluated; the highest median (0.6538) was measured in V. retordii, and the lowest was measured in V. erythrophylla (0.0783). Among the 28 Vitis species in the study, the range of $F_{v} / F_{m}$ values was similar for $V$. piasezkii and $V$. betulifolia, which showed the widest range of all, followed by those for $V$. davidii, $V$. heyneana subsp ficifolia, $V$. adenoclada, and $V$. yunnanensis. For the evaluation results in consecutive three years $(2016,2017$, and 2018), the overall trend is consistent. In 2017, however, the highest $F_{v} / F_{m}$ [Sang 943 (7), 0.6948] was recorded in V. heyneana subsp ficifolia and the lowest $F_{v} / F_{m}$ was measured in $V$. rupestris [Shadi 1117 (228), 0.0866]. On the contrary, in 2018, the highest $F_{v} / F_{m}$ was detected in $V$. heyneana subsp ficifolia [Shibanyan 11 (1), 0.7022], while the lowest $F_{v} / F_{m}$ value was observed in $V$. piasezkii [Laojunshan 1 (105), 0.0896].

\section{Discussion}

With global warming, high temperature stress, as one of the main abiotic stress factors, has a direct or indirect influence on many important grape and wine producing areas in the world. The increase of temperature, on the one hand, advances the growth period of grapes and increases the sugar content of fruits, but on the other hand, it results in premature senescence of leaves and reduction of the quality of grapes or wine [30]. Using the physiological defense mechanism of plants to carry out the breeding of new heat-tolerant varieties is of great significance for plants to resist high temperature stress and solve the problem of plant production under high temperature stress, hence, there is a need for evaluation of high-temperature sensitivity of grapevine [31]. Here, we investigated differences in heat tolerance among 247 grape accessions in response to high ambient temperature by chlorophyll 
fluorescence according to $\mathrm{Xu}$ et al. [10]. The results indicate that the method is practical, efficient, and highly accurate, and the results are consistent in the three years.

In this study, we found that $V$. amurensis originating in the Jilin province of north-eastern China shows highly heat-tolerant, while V. erythrophylla in Jiangxi province of south-eastern China is heat-sensitive. Therefore, we need to revise the previous thought. We speculate that, on the one hand, in a certain historical period in the north, it used to be high-temperature weather, and grapes in the north were domesticated by the high temperature. On the other hand, many plants have cross-adaptation including grapes [32]. Based on the conclusion of this study, the wild species with special excellent characters in the north can be introduced to the south for domestication and cultivation, or the wild species in the north can be used as parents to cultivate heat-resistant grape varieties, which can avoid some disadvantages of grapes in the south. The heat tolerance of most grape species varies greatly, indicating that the grapes have a large variation in the evolution process, and these resources can be used to mine molecular markers of heat tolerance. In addition, the difference of heat tolerance among different accessions in some species is very large (Figure 1), and we may utilize these resources to investigate quantitative trait locus of heat tolerance in grape.

In summary, we evaluated the heat tolerance of 247 grape accessions. The results will provide very valuable information for breeding heat-tolerant grape cultivars and the molecular mechanism of heat tolerance.

Supplementary Materials: The following are available online at http://www.mdpi.com/2311-7524/6/4/0068/s1, Table S1: Heat tolerance of grape accessions or species evaluated using the Chlorophyll a Fluorescence parameter $F_{v} / F_{m}$. Table S2: Heat tolerance of grape accessions or species evaluated using the Chlorophyll a Fluorescence parameter $F_{v} / F_{m}$.

Author Contributions: Conceptualization, Y.L. and C.L.; methodology, Y.L., J.J. and L.W.; software, Y.L., X.F., Y.Z. and J.W.; validation, Y.L., L.W. and C.L.; investigation, Y.L. and J.J.; writing-review and editing: Y.L., L.W. and C.L.; visualization, Y.L.; supervision, L.W. and C.L.; funding acquisition, L.W. and C.L. All authors have read and agreed to the published version of the manuscript.

Funding: This research was supported by the National Key Research and Development Program of China (2018YFD1000300); by the National Key R\&D Program on Monitoring, Early warning, and Prevention of Major National Disaster (2017YFC1502806); by the China Agriculture Research System (CARS-29); and by the Agricultural Science and Technology Innovation Program of the Chinese Academy of Agricultural Sciences (CAAS-ASTIP-2018-ZFRI).

Conflicts of Interest: The authors declare no conflict of interest.

\section{References}

1. Vidya, S.M.; Vijay, K.H.S.; Bhatt, R.M.; Laxman, R.H.; Ravishankar, K.V. Transcriptional profiling and genes involved in acquired thermotolerance in Banana: A non-model crop. Sci. Rep. 2018, 8, 10683. [CrossRef]

2. Greer, D.H.; Weedon, M.M. Can a small differential in canopy temperature influence performance of Semillon in a vineyard? N. Z. J. Crop Hort. Sci. 2018, 47, 63-82. [CrossRef]

3. Webb, L.B.; Whetton, P.H.; Bhend, J.; Darbyshire, R.; Briggs, P.R.; Barlwo, E.W.R. Earlier wine-grape ripening driven by climatic warming and drying and management practices. Nat. Clim. Chang. 2012, 2, 259-264. [CrossRef]

4. Parra, C.S.; Aguirreolea, J.; Sánchez-Díaz, M.; Irigoyen, J.J.; Morales, F. Effects of climate change scenarios on Tempranillo grapevine (Vitis vinifera L.) ripening: Response to a combination of elevated $\mathrm{CO}_{2}$, and temperature, and moderate drought. Plant Soil 2010, 337, 179-191. [CrossRef]

5. Teslić, N.; Zinzani, G.; Parpinello, G.P.; Versari, A. Climate change trends, grape production, and potential alcohol concentration in wine from the Romagna Sangiovese appellation area (Italy). Theor. Appl. Clim. 2018, 131, 793-803. [CrossRef]

6. Ollat, N.; Leeuwen, C.V.; Cortázar-Atauri, I.G.D.; Touzard, J.M. The challenging issue of climate change for sustainable grape and wine production. OENO One 2017, 51, 59-60. [CrossRef]

7. Greer, D.H.; Weston, C. Heat stress affects flowering, berry growth, sugar accumulation and photosynthesis of Vitis vinifera cv. Semillon grapevines grown in a controlled environment. Funct. Plant Biol. 2010, 37, 206-214. [CrossRef] 
8. Zha, Q.; Xi, X.J.; Jiang, A.L.; Wang, S.P.; Tian, Y.H. Changes in the protective mechanism of photosystem II and molecular regulation in response to high temperature stress in grapevines. Plant Physiol. Biochem. 2016, 101, 43-53. [CrossRef]

9. Koutalianou, M.; Orfanidis, S.; Katsaros, C. Effects of high temperature on the ultrastructure and microtubule organization of interphase and dividing cells of the seagrass Cymodocea nodosa. Protoplasma 2016, 253, 299-310. [CrossRef] [PubMed]

10. Xu, H.G.; Liu, G.J.; Liu, G.T.; Yan, B.F.; Duan, W.; Wang, L.J.; Li, S.H. Comparison of investigation methods of heat injury in grapevine (Vitis) and assessment to heat tolerance in different cultivars and species. BMC Plant Biol. 2014, 14, 156-165. [CrossRef]

11. Kadir, S.; Weihe, W.; Alkhatib, K. Photochemical efficiency and recovery of photosystem II in grapes after exposure to sudden and gradual heat stress. J. Am. Soc. Hort. Sci. 2007, 132, 764-769. [CrossRef]

12. Luo, H.B.; Ma, L.; Xi, H.F.; Duan, W.; Li, S.H.; Loescher, W.; Wang, J.F.; Wang, L.J. Photosynthetic responses to heat treatments at different temperatures and following recovery in grapevine (Vitis amurensis L.) leaves. PLoS ONE 2011, 6, e23033. [CrossRef] [PubMed]

13. Camejo, D.; Rodriguez, P.; Morales, M.A.; Dell Amico, J.M.; Torrecillas, A.; Alarcon, J.J. High temperature effects on photosynthetic activity of two tomato cultivars with different heat susceptibility. J. Plant Physiol. 2005, 162, 281-289. [CrossRef] [PubMed]

14. Zha, Q.; Xi, X.J.; Jiang, A.L.; Tian, Y.H. Comparison of the activities of photosystem II of four table grapevine cultivars during high-temperature stress. Hortic. Environ. Biotechnol. 2018, 59, 363-371. [CrossRef]

15. Sage, R.F.; Kubien, D.S. The temperature response of $C_{3}$ and $C_{4}$ photosynthesis. Plant Cell Environ. 2007, 30, 1086-1106. [CrossRef]

16. Baker, N.R. Chlorophyll fluorescence: A probe of photosynthesis in vivo. Ann. Rev. Plant Biol. 2008, 59, 89-113. [CrossRef] [PubMed]

17. Araldi, R.; Corniani, N.; Tropaldi, L.; Gitotto, M.; Belapart, D.; Simoes, P.S. Chlorophyll fluorescence in guanandi tree (Calophyllum brasiliense) after herbicide application. Planta Daninha 2015, 33, 77-82. [CrossRef]

18. Ogaya, R.; Peñuelas, J.; Asensio, D.; Llusia, J. Chlorophyll fluorescence responses to temperature and water availability in two co-dominant Mediterranean shrub and tree species in a long-term field experiment simulating climate change. Environ. Exp. Bot. 2011, 73, 89-93. [CrossRef]

19. Sharma, D.K.; Andersen, S.B.; Ottosen, C.O.; Rosenqvist, E. Phenotyping of wheat cultivars for heat tolerance using chlorophyll a fluorescence. Funct. Plant Biol. 2012, 39, 936-947. [CrossRef]

20. Ehlert, B.; Hincha, D.K. Chlorophyll fluorescence imaging accurately quantifies freezing damage and cold acclimation responses in Arabidopsis leaves. Plant Methods 2008, 4, 1-7. [CrossRef]

21. Sierra-Almeida, A.; Cavieres, L.A. Summer freezing resistance of high-elevation plant species changes with ontogeny. Environ. Exp. Bot. 2012, 80, 10-15. [CrossRef]

22. Perera-Castro, A.V.; Brito, P.; González-Rodríguez, A.M. Changes in thermic limits and acclimation assessment for an alpine plant by chlorophyll fluorescence analysis: $F_{v} / F_{m}$ vs. $\mathrm{R}_{\mathrm{fd}}$. Photosynthetica 2018, 56, 527-536. [CrossRef]

23. Shahsavandi, F.; Eshghi, S.; Gharaghani, A. Physiological responses of two grapevine cultivars to combined drought and high temperature stresses in the presence of arbuscular mycorrhiza. Acta Hortic. 2018, 1190, 45-52. [CrossRef]

24. Jiang, J.F.; Ma, Y.F.; Fan, X.C.; Zhang, Y.; Sun, H.S.; Wang, L.J.; Liu, C.H. Evaluation of 196 Vitis L. germplasm resources to heat tolerance. J. Plant. Gen. Res. 2017, 18, 70-79. [CrossRef]

25. Zhang, J.L.; Cao, Z.Y.; Ma, J.F. Screening of cold-resistant seedlings of a Chinese wild grape (Vitis piasezkii Maxim var. pagnucii) native to loess plateau of eastern Gansu province, China, as rootstocks. Sci. Hortic. 2009, 122, 125-128. [CrossRef]

26. Wang, L.X.; Zhang, F.R.; Li, R.F.; Liang, Y.R.; Liu, Y. The morphologic characteristics of starch grain in grape shoots and its relationship to cold resistance. Acta Hortic. 2000, 27, 85-89.

27. Zhang, J.L.; Xu, R.; Cao, Z.Y.; Wang, S.M.; Ren, J.Z. Factors affecting in vitro propagation of a Chinese wild grape (Vitis piasezkii var. pagnucii): Shoot production and rhizogenesis. N. Z. J. Agric. Res. 2006, 34, 217-223. [CrossRef]

28. Wani, R.A.; Sheema, S.; Dar, N.A.; Angchuk, S.; Parray, G.A. Irrigation regimes effecting drought tolerance of grape root-stocks under cold arid conditions. Int. J. Sci. Technol. Res. 2013, 2, 113-117. 
29. Lavania, D.; Siddiqui, M.H.; Al-Whaibi, M.H.; Singh, A.K.; Kumar, R.; Grover, A. Genetic approaches for breeding heat stress tolerance in faba bean (Vicia faba L.). Acta Physiol. Plant 2015, 37, 1-9. [CrossRef]

30. De-Orduna, R.M. Climate change associated effects on grape and wine quality and production. Food Res. Int. 2010, 43, 1844-1855. [CrossRef]

31. Zha, Q.; Xi, X.J.; He, Y.N.; Jiang, A.L. Comprehensive evaluation of heat resistance in 68 Vitis germplasm resources. Vitis 2018, 57, 75-81. [CrossRef]

32. Wang, L.J.; Loescher, W.; Duan, W.; Li, W.D.; Yang, S.H.; Li, S.H. Heat acclimation induced acquired heat tolerance and cross adaptation in different grape cultivars: Relationships to photosynthetic energy partitioning. Funct. Plant Biol. 2009, 36, 5116-5526. [CrossRef] [PubMed]

Publisher's Note: MDPI stays neutral with regard to jurisdictional claims in published maps and institutional affiliations.

(C) 2020 by the authors. Licensee MDPI, Basel, Switzerland. This article is an open access article distributed under the terms and conditions of the Creative Commons Attribution (CC BY) license (http://creativecommons.org/licenses/by/4.0/). 